\title{
Investigação e análise da história social e das aparências do vestuário de homens negros no período pós-abolição da escravatura no Brasil
}

\author{
Investigation and analysis of the social history and appearances of black \\ men'sclothing in the post-slavery abolition period in Brazil
}

\author{
Ronaldo Salvador Vasques ${ }^{1 *}$, Silvia Mara Bortoloto Damasceno Barcelos ${ }^{1}$, Clara Damasceno \\ Zandona $^{1}$, Fabrício de Souza Fortunato ${ }^{1}$, Márcia Regina Paiva de Brito ${ }^{1}$
}

\begin{abstract}
RESUMO
Essa pesquisa busca identificar, por meio do vestuário do século XIX (pós-abolição no Brasil), a vestimenta de homens negros. Propõe investigar os vestuários usados por Machado de Assis, Lima Barreto e André Rebouças a partir de 1888. Desse modo, a investigação tem por objetivo identificar quais eram as roupas e os adornos usados por eles no respectivo período. Documentos, cartas, fotografias e decodificações de revistas oitocentistas foram pesquisados e analisados, principalmente a Revista Illustrada, a Semana Ilustrada e a Brasiliana Fotográfica, bem como os textos publicados e as roupas utilizadas. As bases teóricas utilizadas foram pautadas, principalmente, nas obras de Gilda de Mello e Souza (1987) e John Harvey (1997). O século XIX modificou notoriamente a moda masculina na Europa e no Brasil, influenciada especialmente pelo estilo inglês. Mediante esta pesquisa, pretende-se identificar essa influência, alinhavar a moda e a história e entender a evolução da vestimenta de homens negros no período supracitado no Brasil.
\end{abstract}

Palavras-chave: Vestuário masculino; Homens negros; Pós-abolição - Brasil;

\begin{abstract}
This research seeks to identify, through the clothing of the nineteenth century (post-abolition in Brazil), the clothing of black men, it proposes to investigate the clothing used by Machado de Assis, Lima Barreto and André Rebouças from 1888 onwards. The investigation aims to identify what were the clothes and adornments used by them in the respective period. Documents, letters, photographs and decodings from nineteenth-century magazines were researched and analyzed, mainly Revista Illustrada, Semana Ilustrada and Brasiliana Fotográfica, as well as the published texts and the clothes used. The theoretical bases used were based mainly on the works of Gilda de Mello and Souza (1987) and John Harvey (1997). The 19th century markedly changed men's fashion in Europe and Brazil, especially influenced by the English style. Through this research, it is intended to identify this influence, to tack together fashion and history, and to understand the evolution of black men's clothing in the aforementioned period in Brazil.
\end{abstract}

Keywords: Men'sclothing; Black men; Post-abolition - Brazil;

${ }^{1}$ Universidade Estadual de Maringá. Campus Reginal de Cianorte. Departamento de Design e Moda.

*E-mail: rsvasques@uem.br 


\section{INTRODUÇÃO}

Neste recorte de tempo, a moda masculina, bem como as transformações nos meios sociais, culturais, econômicos e políticos, sofrem diversas mutações, apropriando-se de estilos estrangeiros.

E o vestir masculino? Como este entra na história e memória no Brasil? A socióloga Gilda de Mello e Souza, estudiosa do século XIX, comenta sobre o vestuário masculino do Brasil dentro do relativo período. Souza (1987), em O Espírito das Roupas, têm uma propensão a trabalhar com elementos da moda e suas variações, estudando as particularidades das roupas e a maneira na qual elas se alteram dentro do ínterim de transições ao final do século XIX. Este período, cujas transformações nos meios sociais, culturais, econômicos e de produção adquirem uma vasta importância na sociedade, é de incomparável pertinência à história da moda, haja vista que a estética das roupas masculinas transgride ao estilo minimalista.

Essa pesquisa teve como objetivo identificar por meio do vestuário do século XIX (pós-abolição no Brasil), a vestimenta de homens negros, propõe investigar os vestuários usados por Machado de Assis, Lima Barreto e André Rebouças a partir de 1888.

Sendo assim, a vestimenta masculina brasileira do século XIX, ainda que sóbria, portava-se com certa extravagância. Diante da importância da Moda, tomada como fonte indiscutível de evoluções e transformações nas roupas, a partir da metade do século XIX até o início do século XX, no mundo Ocidental, o novo homem oitocentista, comparado a sua figura no século XVIII. À vista disso, os trajes masculinos passam a ser enxutos, sóbrios, sérios e escuros.

Contudo, a marca de uma moda masculina despretensiosa, porém esbelta, não vagou somente pela Inglaterra, apesar de muitos historiadores considerá-la o centro da moda durante o período aqui discutido. Coincidindo com roupas semelhantes aos moldes, às cores, aos cortes e aos ornamentos da nação do estilo, o Brasil compactuou, à indumentária e moda masculinas emergentes da Europa, principalmente os costumes e modas inglesas.

Desse modo, os homens priorizaram moldes finos e sóbrios, os quais portavam caimentos verticais, cortes retos, cores frugais e ostentavam acessórios de acabamento como abotoaduras, entre outros aviamentos fortes da época. 
O traje propunha para homens que o vestia modernidade, elegância e arrogância, mas de elevado bom gosto. Cabe ressaltar que o traje desses homens ficou conhecido e marcado como um dos mais importantes vestuários do século XIX, o dandismo se tornou uma indumentária clássica.

\section{METODOLOGIA}

As pesquisas históricas proporcionam, o conhecimento do presente. Para essa compreensão, torna-se essencial a análise de materiais disponíveis no espaço tempo da época estudada. Neste sentido, este projeto faz uso da metodologia historiográfica, exposta em figuras ilustrativas dos trajes da época, revistas, fotografias, jornais, livros e textos publicados por Machado de Assis, André Rebouças e Lima Barreto, os quais trazem registros e relatos históricos do século XIX. Diante disso, faz-se possível verificar o cenário dos vestuários masculinos negros no período de pós-abolição e, consequentemente, o contexto social e histórico cultural da época. Ao todo, o projeto contém o uso de referências bibliográficas disponíveis em bancos de dados científicos, não só da época, mas também de documentos recentes, onde intelectuais escrevem suas descobertas sobre o período, bem como os textos dos autores supracitados acima.

\section{CONTEXTO HISTÓRICO DA SOCIEDADE BRASILEIRA E O VESTUÁRIO} MASCULINO A PARTIR DE 1888

Neste recorte de tempo, a moda masculina, bem como as transformações nos meios sociais, culturais, econômicos e políticos, sofrem diversas mutações, apropriando-se de estilos estrangeiros.

O século XIX foi um período no qual os centros urbanos se expandiram e a modernidade efetivamente transformou a vida das pessoas. A moda do século XIX propôs, de início, livrar as mulheres da moda de tempos anteriores, com os exageros nos volumes e os pesos das roupas, as saias extremamente grandes e os penteados enormes, entre outros. Após a coroação de Napoleão Bonaparte em 1804, o estilo império impôs-se por toda Europa e, em consequência, surgiu o 'vestido Império' que ficou conhecido através dos trajes de Josefina de Beauharnais, a primeira esposa de Napoleão (VASQUES, 2018, p.45).

E o vestir masculino? Como este entra na história e memória no Brasil? A socióloga Gilda de Mello e Souza, estudiosa do século XIX, comenta sobre o vestuário masculino do Brasil dentro do relativo período. Souza (1987), em O Espírito das 
Roupas, têm uma propensão a trabalhar com elementos da moda e suas variações, estudando as particularidades das roupas e a maneira na qual elas se alteram dentro do ínterim de transições ao final do século XIX. Este período, cujas transformações nos meios sociais, culturais, econômicos e de produção adquirem uma vasta importância na sociedade, é de incomparável pertinência à história da moda, haja vista que a estética das roupas masculinas transgride ao estilo minimalista. Isto porque, para Souza (1987), os homens brasileiros passam a preferir, por influência européia, roupas sóbrias e escuras como a toilette - conjunto de peças - que compunha apenas casaco, colete e calças.

No que se referem à moda, os vestuários e os textos dos escritores e ensaístas Machado de Assis, Lima Barreto e André Rebouças, figuras ilustres que marcaram a história do século XIX e XX, cada qual contribuindo à moda dentro de seu viés singular, ajudam a analisar e descrever sistematicamente o vestuário dos homens negros a partir do final do período oitocentista. Desse modo, a literalidade de Machado de Assis e Lima Barreto e as cartas escritas pelo reformador social, André Rebouças, durante seu exílio na África, são ferramentas-chave para que possamos compreender a fundo a manifestação da moda masculina brasileira embasada em um contexto histórico-cultural guarnecido de mudanças.

O realismo machadiano e as críticas sociais descritas nas obras de Machado de Assis como em Memórias póstumas de Brás Cubas (1880) adentram para o entendimento e compreensão de uma época em que a postura e o comportamento do indivíduo, perante a sociedade, determinariam sua integridade e poses. Conforme a Academia Brasileira de Letras, Joaquim Maria Machado de Assis nasceu no Rio de Janeiro, RJ, em 21 de junho de 1839, e faleceu também no Rio de Janeiro, em 29 de setembro de 1908. Como escritor, teve uma forte influência no período, com suas mensagens retóricas e concisas, descrevendo fielmente, por meio da ficção, os costumes, as crenças, as relações e os vestuários descritos e estipulados ao final do século XIX. Para tanto, serão investigados os textos e os trajes desses três personagens da história do século XIX.

Partindo da mesma premissa carioca, o escritor e jornalista Afonso Henriques de Lima Barreto, nasceu em 13 de maio de 1881 no Rio de Janeiro, RJ, e faleceu também no Rio de Janeiro, no dia $1^{\circ}$ de novembro de 1922. Dispondo-se de um célebre biógrafo, Francisco de Assis Barbosa dedicou anos de sua vida estudando a vida e as obras do 
escritor carioca, homenageando-o com o livro A Vida de Lima Barreto (1988). Em sua obra, Barbosa conceitua Lima Barreto como um homem sóbrio que retratava as mazelas do período de maneira límpida e autêntica, compactuando com a sua consciência na qual se aceitava como um homem que se apresenta dentro de uma "[...] tripla marginalidade - preto, pobre e suburbano -, o que faria do preconceito e da discriminação os temas dominantes de sua literatura, prenhe de traços autobiográficos, que aborda recorrentemente a questão da exclusão social dos negros e seus descendentes" (ALMEIDA NETO; MACHADO, 2001, p. 208).

Em face da escrita, Lima Barreto confessa e concede, também, seus posicionamentos ideológicos, levando às obras literárias vertentes sócio-políticoculturais. No entanto, entregou mais do que apenas assuntos externos de uma sociedade oitocentista com aptidão discriminante. Tratou de vivências pessoais perante uma vida sofrida, por conseguinte, foi chamado de "triste visionário" por Schwarcz (2017, p. 1). O romancista faz uma representação alegórica do seu tempo, isso se dá devido ao período em que viveu, “[...] marcado por importantes transformações econômicas, políticas, sociais e culturais no Brasil (1881-1922)" (ALMEIDA NETO; MACHADO, 2001, 207). Uma prova disso foi seu aniversário de sete anos, comemorado no dia da assinatura da Lei Áurea, no dia 13 de maio de 1888.

Por fim, acerca da luta contra a escravidão e de uma vida debruçada a ideais abolicionistas, temos o influente Negro André - forma como André Rebouças se referiu a si mesmo em uma de suas cartas escrita em outubro de 1891, em Cannes, na África (SOARES, 2017) - foi um homem memorável e pertinente à história. André Pinto Rebouças nasceu durante a Guerra de Sabinada - revolta separatista baiana - em janeiro de 1838 e morreu em 1898 em Funchal, na Ilha da Madeira. O reformador era amigo íntimo do imperador Pedro II, o que o tornara pertencente à elite intelectual do Segundo Reinado. Contudo, André foi contra os ideais político-sociais da época, haja vista que era um “[...] homem negro de grande prestígio intelectual no contexto de escravidão e pós-escravidão.” (SOARES, 2017, 243).

Logo após a proclamação da República (1889), André Rebouças acompanhou a Família Imperial no exílio e, durante seu autoexílio (1889-1898), passou a escrever cartas, as quais continham conteúdo expondo as mazelas vividas por “[...] negros, mestiços livres e imigrantes na sociedade brasileira em contextos de escravidão e de pós-abolição" (SOARES, 2017, p. 244). André disponibilizou um conteúdo riquíssimo 
para os investigadores de sua vida e do período em que viveu, por meio de seu Diário pessoal e dos Registros de correspondência, eternizou sua luta por uma reforma social.

Em concordância com o período aqui explorado, juntamente às análises dos textos e vestimentas das três épicas figuras citadas acima, a Revista Illustrada permite realizar uma investigação capaz de interpretar os vestuários escritos e adequados aos séculos XIX e XX. A Revista Illustrada, na qual se realiza um apanhado histórico da trajetória jornalística em revistas e é considerada uma das fontes de informações mais relevantes das respectivas épocas, era responsável por repercutir e elucidar as eventualidades de um Brasil sinalizado por vários acontecimentos sociais, políticos e culturais como, por exemplo, a abolição da escravatura e o fim do período monárquico.

Com cunho político, a Revista Illustrada foi criada por Angelo Agostini em 1876, no Rio de Janeiro. Agostini nasceu em Vercelli, Itália, em 1843. Frequentou academias de arte e estudou desenho e pintura em Paris. Em 1859, veio para o Brasil, situando-se em São Paulo e, em setembro de 1867, mudou-se para o Rio de Janeiro, onde desenvolveu as ilustrações mais notáveis de sua carreira, atingindo um leitorado ainda maior. De acordo com Costa (2007, p. 160), Angelo Agostini "foi jornalista, repórter, editor e militante político, mas foi como cartunista que se consagrou, sendo apontado como um dos inventores mundiais das histórias em quadrinhos". Entre textos e charges, o ilustrador obteve muitos méritos e agradou nomes de suma importância para o Brasil da época como Monteiro Lobato, o qual o elogiou, reportando que seus desenhos atingiam às diversas classes, de maneira leve e perspicaz.

Destarte, com base fundamentada em uma análise investigativo-descritiva de textos literários e textos publicados em periódicos, compreende-se que o século XIX foi um cenário "[...] fértil para múltiplas transformações na moda, sinalizando um reflexo do novo pensamento da época em questão, repleto de mudanças de ordem socioeconômica [...]" (ORSI; ALMEIDA, 2019, p. 197) ocasionadas por fortes mudanças sociais. Conforme as mesmas autoras (2019), a moda expressa à identidade do indivíduo e descreve o mundo ao seu redor, logo, utilizar-se do léxico como elemento fundamental para interpretar estilos e usos passados, suplementa as averiguações desejadas e oferta novas maneiras de exploração. Sendo assim, por meio do estudo da Revista Illustrada e de figuras ilustres dos séculos XIX e XX, seguidos de suas obras, e da investigação do vestuário-escrito, o qual possui a finalidade de descrever a moda em nível vocábulo, assim fundamentado pelo sociólogo francês 
Roland Barthes (2009) em seu livro Sistema da moda, é possível engrandecer as erudições da moda e vestimenta masculina brasileira entre negros intelectuais e os demais influentes no período pós-abolição.

\section{A REVISTA ILLUSTRADA E OS TEXTOS REFERENTES À INDUMENTÁRIA E MODA MASCULINA DO SÉCULO XIX}

Designada a ofertar conteúdos literários, ilustrativos e também de cunho político, a Revista Illustrada, criada pelo ilustrador Angelo Agostini, oferece informações verazes e suntuosas da sociedade brasileira do século XIX. Em conformidade aos assuntos tratados, ainda hoje, em revistas, jornais, entre outros materiais de vertente informativa e periódica, as publicações da Revista condiziam às ocorrências mais relevantes da época, juntamente às novidades que, quando manifestadas, abordavam diversas temáticas, dentre elas, a moda, ainda que de maneira fragmentada.

À exceção da dinâmica de elementos que compunham as páginas da Revista como charges, poemas, contos, matérias que sintetizavam os acontecimentos sociais, culturais, artísticos, políticos e econômicos da semana, eram recorrentes sátiras artísticas e desenhos críticos por meio de caricaturas fiéis às pessoas retratadas. Entre elas, podem-se citar pessoas comuns, políticos e, principalmente, membros da Igreja, os quais eram "perseguidos" por Angelo Agostini, haja vista que, segundo Costa (2007, p. 185), este prestava claramente ao anticlericalismo. Contudo, servindo-se das ilustrações caricatas, faz-se possível analisar as vestimentas de todas as personagens humanas presentes nas publicações Revista.

Logo, reconhecem-se as típicas peças das vestimentas masculinas da época, observadas, também, por meio do vestuário-escrito. Retirado da matéria denominada Echos e Notas, escrita por Farfarello (1892, p. 03) na edição 638 da Revista Illustrada, o seguinte recorte revela algumas peças masculinas essenciais da época: "Elles lá vão passando [...] trajando sobrecasaca de diagonal, collarinhos claros de gomma, camisas abotoadas a brilhantes, cartola, calças brancas e botinas de bezerro, reluzentes [...]" (REVISTA ILLUSTRADA, s/d). A partir desta breve análise verossímil dos elementos que compunham a peça inteiriça dos homens do século XIX, percebe-se a preferência que eles mesmos tinham, ao definirem os trajes ideais para cumprirem com suas rotinas.

Dessa forma, pautadas em um estilo conservador trajado de simetria, com sobreposições de peças formais como, sobretudo, casaco e colete, cores modestas que 
oscilavam dentro da gama de tons neutros, cartolas e sapatos escuros - muitas vezes referenciados por "botinas" dentro dos textos da Revista Illustrada - as vestimentas masculinas do século XIX sofreram notórias transformações em relação às vestimentas dos homens do século XVIII. Isto se deu em consequência da intervenção da indumentária inglesa, parâmetro para as modas daqueles tempos a partir da segunda metade do século XIX, e, principalmente, pelas mudanças estruturais e políticas que alvejaram integralmente a sociedade brasileira ao final deste século. Portanto, sabe-se que a indumentária e moda sempre acompanharão as transições históricas, basta ver que a roupa é o objeto de maior proximidade ao corpo, alterando-se conforme as eventualidades do período em que se encontra e as emoções que acompanham essas recorrentes transformações.

Desse modo, sabido da descrição condizente à realidade do século XIX ofertada pela Revista Illustrada, faz-se possível identificar a moda brasileira do homem negro no período de pós-abolição. Esses se compunham de elementos mais discretos, tendo em vista que as roupas e os cuidados pessoais não deixaram de ser importantes para eles. Contudo, para os mais abastados, o luxo não fora deixado de lado, a predileção por tecidos nobres e matérias-primas preciosas continuaram a fazer parte do bom gosto masculino. Confirma-se isso proferindo o conto nomeado Fenianos, escrito por Marcial (1888, p. 03) à edição 485 da Revista Illustrada: “[...] representava elle um manto de seda azul, bordado a ouro [...]" (REVISTA ILLUSTRADA, s/d). Sendo assim, a vestimenta masculina brasileira do século XIX, ainda que sóbria, portava-se com certa extravagância.

\section{A MODA E A INDUMENTÁRIA MASCULINA NA INGLATERRA E NO BRASIL}

Propagando um estilo sóbrio e cortes, o preto foi a nuance característica da moda masculina oitocentista.

Começo no século XIX por que foi nesse período, mais do que em qualquer momento anterior, que os homens vestiam preto; e também porque essa é a época em que o preto da roupa masculina é percebido como problemático - algo que intriga os homens, ao mesmo tempo em que se vestiam de negro. O preto servia evidentemente de distinção entre os sexos: o que incomodava comentaristas da época não era isso, mas o fato de que, cada vez mais, os homens pareciam optar pela vestimenta da morte (HARVEY, 2003, p. 29). 
Em A Cultura das Aparências: uma história da indumentária (séculos XVII XVIII), Roche (2007, p. 70) afirma que, "no caso dos homens, uma completa mudança de direção teve início com a adoção das calças e do casaco, de um certo asseio e rigidez, de uma austeridade na forma, no tecido e na cor. O preto triunfou" e corroborando com Roche, Harvey (2003, p. 30) diz que "os homens usavam cores no século XVIII, e mesmo nas primeiras décadas do XIX. Mas, a partir de então, a roupa masculina tornase cada vez mais austera e mais escura".

Mediante comentário de Roche (2007), pautado no estudo das roupas masculinas do início do século XIX, observa-se a continuidade do estilo até o final do respectivo período. Não somente na Europa como também no Brasil, a sobriedade das roupas não partiu de um pressuposto sem fundamentos, pelo contrário, ela se estabelece dentro de um contexto sócio-histórico que impactou inúmeras partes do mundo, relacionando-se ao industrialismo e à modernidade. Desse ponto de vista, torna-se pertinente discorrer sobre as revoluções nos meios de produção, consideradas um reflexo de uma transformação nos meios sociais, culturais e econômicos da sociedade inglesa da época.

Durante a segunda metade do século XIX, a Europa Ocidental vivia um vasto desenvolvimento na linha produtiva de diferentes segmentos, dentre eles, a evolução da indústria têxtil. Em razão de a Moda atuar como uma crítica feroz ao sistema e estar presente em tudo aquilo que rege um período, houve a incisão da deliberação e difusão de vestimentas modernas sobre as relações sociais e suas vertentes. Pertinente a isto, é de comum concordância a inserção da Moda entre os principais elos construtores da economia de um país (ROCHE, 2007, p. 57).

Diante da importância da Moda, tomada como fonte indiscutível de evoluções e transformações nas roupas, a partir da metade do século XIX até o início do século XX, no mundo Ocidental, o novo homem oitocentista, comparado a sua figura no século XVIII, sofreu “[...] novas convenções sociais, entre elas, a banalização do luxo ostentatório entre a aristocracia, a projeção do corpo humano como extensão do trabalho e a condenação do homossexualismo em países como a Inglaterra, a partir do século XVIII [...]" (BRANDINI, 2016, p. 03). À vista disso, os trajes masculinos passam a ser enxutos, sóbrios, sérios e escuros.

Contudo, a marca de uma moda masculina despretensiosa, porém esbelta, não vagou somente pela Inglaterra, apesar de muitos historiadores considerá-la o centro da moda durante o período aqui discutido. Coincidindo com roupas semelhantes aos 
moldes, às cores, aos cortes e aos ornamentos da nação do estilo, o Brasil compactuou, também, à indumentária e moda masculinas emergentes da Europa, principalmente os costumes e modas inglesas.

Entretanto, de acordo com Orsi e Almeida (2019, p. 199)

As vestimentas no Brasil sofreram alterações de acordo com as especificidades locais como, por exemplo, o clima, que fez com que as roupas fossem confeccionadas em tecidos mais leves. Ademais, a cultura dos negros e indígenas também incidiu fortemente sobre a cultura do povo brasileiro.

Desse modo, os homens priorizaram moldes finos e sóbrios, os quais portavam caimentos verticais, cortes retos, cores frugais e ostentavam acessórios de acabamento como abotoaduras, entre outros aviamentos fortes da época. Assim, para que houvesse uma especulação mais aprofundada sobre cada um dos pormenores que trouxeram a elegância e sofisticação que marcaram as roupas masculinas do século XIX, foram estudadas fontes exclusivas do Brasil oitocentista, concedendo a veracidade dos fatos. Afinal, “[...] como bem expressa Machado de Assis (1884), no conto Capítulo dos Chapéus, o acessório errado pode trazer a ruína para o homem da boa sociedade [...]" (SIMILI; BONADIO, 2017, p. 11), assim como uma investigação pouco satisfatória.

Figura 1- Estilo Dândi

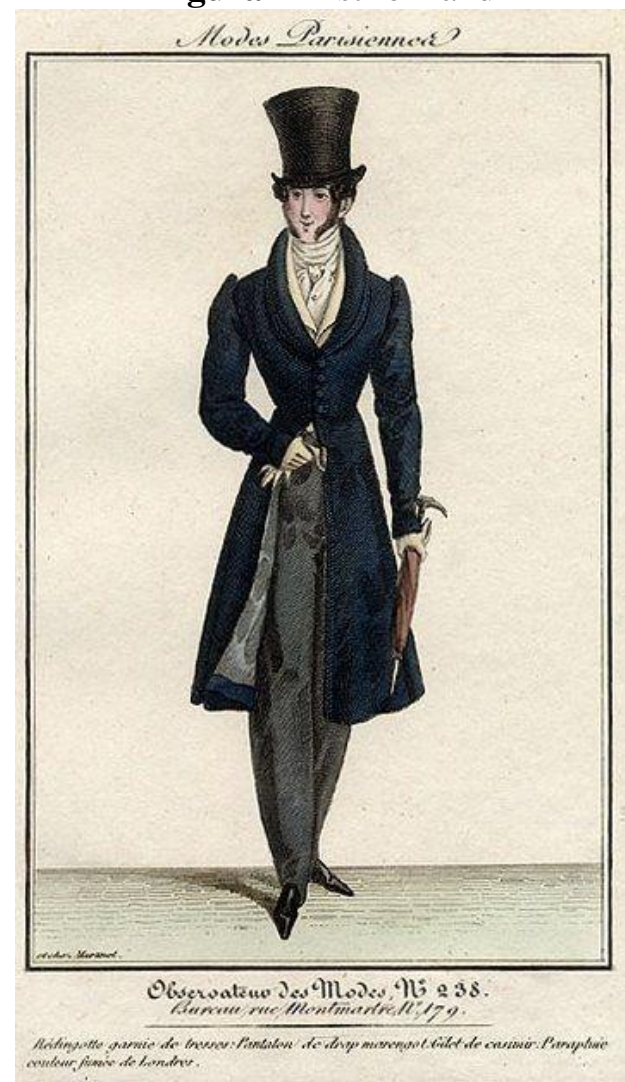

Fonte: Zinne's Blog (2014) 
E por último temos que fomentar sobre o dandismo, estilo importante para a vestimenta masculina no século XIX. Entre os precursores, temos o escritor Oscar Wilde e o primeiro dândi e mais conhecido na moda, Beau Brumell. Segundo Harvey (2003, p. 37) "ele vivia para a elegância, tinha um alfaiate para o casaco, outro para o colete, um terceiro para as calças. $\mathrm{O}$ detalhe mais frequentemente lembrado é que ele passava a maior parte da manhã buscando o perfeito nó de gravata". Brumell tinha coleções de gravatas, mas o traje em si era simples e composto por calças, casaco e colete, entretanto, tinha o melhor talho e o melhor tecido. O traje propunha para homens que o vestia modernidade, elegância e arrogância, mas de elevado bom gosto. “À noite, Brumell aparecia de sobrecasaca preta e calças pretas muito justas: em gravuras da época, ele faz uma figura tão severa que pode parecer até um pouco satânico" (HARVEY, 2003, p.38). Cabe ressaltar que o traje desses homens ficou conhecido e marcado como um dos mais importantes vestuários do século XIX, o dandismo se tornou uma indumentária clássica.

\section{CONCLUSÃO}

Este projeto de iniciação científica está fazendo uma breve discussão inicial sobre a Investigação e análise da história social e das aparências do vestuário de homens negros no período pós-abolição da escravatura no Brasil. Em virtude da Lei Áurea, assinada pela Princesa Isabel, em 1888, a investigação partirá de vestuários e costumes de negros alforriados nesse período, visando estritamente três grandes personalidades desse tempo: Machado de Assis, Lima Barreto e André Rebouças. Desse modo, como base de estudos será apurada a Revista Illustrada, na qual haverá um aprofundamento sobre moda e a própria circulação na revista. A fim de obter, também, resultados histórico-culturais de um período caracterizado por grandes acontecimentos, será examinada a Revolução Industrial e toda sua trajetória vinculada à moda oitocentista. Nesse contexto, observam-se a importância de análises como as empreendidas nesta pesquisa, mencionando, ainda, o contexto da Era Vitoriana, marcado a partir da próspera década de 1850-1870, na Europa - período de grandioso apreço no vestir masculino, onde novos conceitos foram guarnecidos diante das mudanças no contexto social e econômico da época. Isto posto, mantém-se firme o estilo dândi que percorre todo o século XIX, estipulando a sobriedade e a imponência louváveis, tornando os homens que incorporavam esse estilo reconhecidos não somente 
pelo composto calça, casaco, colete e cartola, mas, especialmente, o adorno primordial ao se fomentar sobre o referido estilo, o plastron, muitas vezes se diferenciando das cores integralmente sóbrias do traje que cominava a arrogância.Atrelado a isso, nesse período, as roupas masculinas se bifurcaram, categorizando-se emtrajes para o dia e trajes para a noite. Os trajes diurnos eram roupas práticas para o trabalho; os trajes noturnos eram os chamados fraques, com gravata branca e gola bem alta na nuca, além da recorrente e escura cartela de cores.

\section{REFERÊNCIAS}

ALMEIDA NETO, Luiz Mello de; MACHADO, Maria Cristina Teixeira. Lima Barreto: um pensador social na Primeira República. Sociedade e Cultura, Goiânia, v. 4, n. 2, p. 207-210, 2001.

BARTHES, Roland. Sistema da Moda. São Paulo: Martins Fontes, 2009.

BRANDINI, Valéria. Moda, Comunicação e Modernidade no Século XIX: a fabricação sociocultural da imagem pública pela moda na era da industrialização. Interin, Curitiba, v. 6, n. 2, p. 1-16, 2016.

COSTA, Carlos Roberto da. A revista no Brasil, o século XIX. 2007. Tese (Doutorado em Ciências da Comunicação) - Universidade de São Paulo, São Paulo, 2007.

HARVEY, John. Homens de Preto. São Paulo: Editora UNESP, 2003.

ORSI, Vivian; ALMEIDA, Merciele Cristina. Moda e literatura no Brasil: considerações sobre o léxico do século XIX. Caligrama: Revista de estudos românicos, Belo Horizonte, v. 24, n. 2, p. 193-207, 2019.

REVISTA ILLUSTRADA - 1876 A 1898. s/d. Disponível em: http://hemerotecadigital.bn.br/acervo-digital/revista-illustrada/332747. Acesso em: 18 fev. 2021.

ROCHE, Daniel. A cultura das aparências: uma história da indumentária (séculos XVII-XVIII). São Paulo: Ed. Senac, 2007.

SCHWARCZ, Lilia Moritz. Lima Barreto: triste visionário. São Paulo: Companhia das Letras, 2017.

SIMILI, Ivana Guilherme; BONADIO, Maria Claudia. Histórias do vestir masculino: narrativas de moda, beleza, elegância. Maringá, PR: Eduem, 2017.

SOARES, Anita Maria Pequeno. O Negro André: a questão racial na vida e no pensamento do abolicionista André Rebouças. Plural, Rio de Janeiro, v. 24, p. 242-269, 2017. 
SOUZA, Gilda de Mello e. O espírito das roupas: a moda no século dezenove. São Paulo, SP: Companhia das Letras, 1987.

VASQUES, Ronaldo Salvador. Identificação e análise do vestuário/têxteis presente em museus do traje e moda do século XIX. Tese (Doutorado em Engenharia Têxtil) Universidade do Minho Escola de Engenharia. Guimarães-Portugal, 2018.

ZINNE'S BLOG. Mens regencyfashion 1820-1825. 2014. Disponível em:

http://zinneart.blogspot.com/2014/07/mens-regency-fashion-1820-1825.html. Acesso em: 11 out. 2021.

Recebido em: 10/10/2021

Aprovado em: 10/11/2021

Publicado em: 18/11/2021 